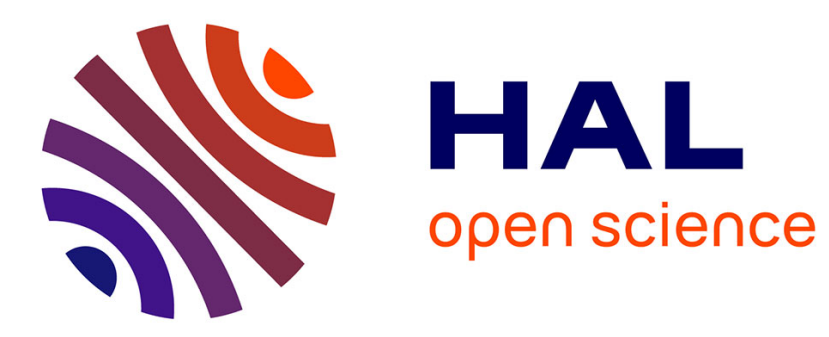

\title{
The relation between students' epistemological understanding of computer models and their cognitive processing on a modelling task
}

Patrick Sins, Wouter R. van Joolingen, Elwin Savelsbergh, Bernadette van Hout-Wolters

\section{To cite this version:}

Patrick Sins, Wouter R. van Joolingen, Elwin Savelsbergh, Bernadette van Hout-Wolters. The relation between students' epistemological understanding of computer models and their cognitive processing on a modelling task. International Journal of Science Education, 2009, 31 (09), pp.1205-1229. 10.1080/09500690802192181. hal-00516238

\section{HAL Id: hal-00516238 \\ https://hal.science/hal-00516238}

Submitted on 9 Sep 2010

HAL is a multi-disciplinary open access archive for the deposit and dissemination of scientific research documents, whether they are published or not. The documents may come from teaching and research institutions in France or abroad, or from public or private research centers.
L'archive ouverte pluridisciplinaire HAL, est destinée au dépôt et à la diffusion de documents scientifiques de niveau recherche, publiés ou non, émanant des établissements d'enseignement et de recherche français ou étrangers, des laboratoires publics ou privés. 


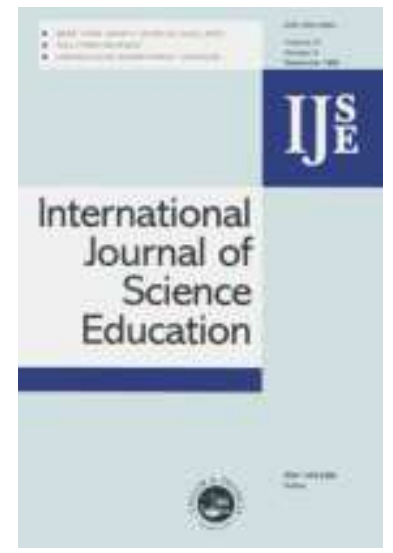

The relation between students' epistemological understanding of computer models and their cognitive processing on a modelling task

\begin{tabular}{|r|l|}
\hline Journal: & International Journal of Science Education \\
\hline Manuscript ID: & TSED-2008-0132 \\
\hline Manuscript Type: & Research Paper \\
\hline Keywords: & science education, model-based learning, reasoning \\
\hline Keywords (user): & $\begin{array}{l}\text { computer-based modelling, Epistemological understanding, } \\
\text { Cognitive processing }\end{array}$ \\
\hline
\end{tabular}

\section{S) ScholaroNE \\ Manuscript Central}




\begin{abstract}
While many researchers in science education have argued that students' epistemological understanding of models and of modelling processes would influence their cognitive processing on a modelling task, there has been little direct evidence for such an effect. Therefore, this study aimed to investigate the relation between students' epistemological understanding of models and modelling and their cognitive processing (i.e. deep versus surface processing) on a modelling task. Twenty-six students, working in dyads, were observed while working on a computer-based modelling task in the domain of physics. Students' epistemological understanding was assessed on four dimensions (i.e. nature of models, purposes of models, process of modelling, and evaluation of models). Students' cognitive processes were assessed based on their verbal protocols, using a coding scheme to classify their types of reasoning. The outcomes confirmed the expected positive correlation between students' level of epistemological understanding and their deep processing $(\underline{r}=0.40$, $\underline{p}=0.04)$, and the negative correlation between level of epistemological understanding and surface processing $(\underline{r}=-0.51, \underline{p}=0.008)$. From these results, we emphasise the necessity of considering epistemological understanding in research as well as in educational practice.
\end{abstract}




\section{Introduction}

Models of scientific phenomena take a central place in contemporary views of science education (e.g. Gilbert \& Boulter, Rutherford, 1998; Raghavan, Satoris, \& Glaser, 1998; Schecker, 1993; Stratford, 1997; White \& Frederiksen, 1998; Zaraza \& Fisher, 1999). Several authors have argued that the activity of building and revising such models is particularly well suited to provide meaningful learning experiences. For instance, some emphasise the opportunity for students to think scientifically about the behaviour of complex phenomena (e.g. Bliss, 1994; Jackson, Stratford, Krajcik, \& Soloway, 1996; Hestenes, 1997; Spector \& Davidson, 1997; Verhoeff, Waarlo, \& Boersma, 2008; Wild, 1996). Others state that if students are allowed to construct models themselves, they can not only reflect upon the science content they are supposed to learn, but also upon the nature of their own knowledge (e.g. Hogan \& Thomas, 2001; Jonassen, Strobel, \& Gottdenker, 2005; Spector, 2000). According to this argument, models offer students the means to externalise and to test their own mental representations of particular scientific phenomena (Coon, 1988; Doyle \& Ford, 1998; Penner, 2001).

However, the benefits of engaging students in modelling activities may only be realised if students understand the nature and the purpose of models in science, as well as comprehend how models are constructed (Justi \& Gilbert, 2002; Treagust, Chittleborough, \& Mamiala, 2002). Such understanding may help students in using and in developing models, since it is assumed that students' epistemological understanding about models and the process of modelling is related to how they approach the material and ultimately to what they learn (Driver, Leach, Millar, \& Scott, 1996; Gobert \& Discenna 1997; Hammer, 1994; Schwarz \& White, 2005; Van Driel \& Verloop, 1999). For instance, Crawford \& Cullin (2004) postulated that a weak epistemological understanding may act to constrain students in using and in developing scientific models. In accordance, several authors have argued that students' 
epistemological understanding has an effect on their cognitive processing during modelling (e.g. Hofer, 2001; Hofer \& Pintrich, 1997; Schwarz, 2002a; Windschnittl \& André, 1998).

Although there is ample evidence to suggest that students' epistemological understanding of models and the process of modelling tends to be quite limited(e.g. Gobert, Snyder, \& Houghton, 2002; Grosslight, Unger, Jay, \& Smith, 1991; Roth \& Roychoudhury, 1994; Ryder \& Leach, 1999; Songer \& Linn, 1991), there has been little evidence to demonstrate the direct relation between students' epistemological understanding and the quality of their modelling processes. If such a relationship could be confirmed, this would lend credibility to efforts aimed at advancing students' epistemological understanding of models and the process of modelling (e.g., Schwarz \& White, 2005). The present study investigates the relationship between students' level of epistemological understanding and the level of their cognitive processing during computer-based scientific modelling.

The epistemological status of models in science

The assessment of students' epistemological understanding will be based on a conceptualisation of how experts perceive models and the process of modelling. Scientists design models with a particular scientific purpose in mind, such as explaining, visualizing, or predicting the behaviour of a scientific phenomenon (Giere, 1990; Gilbert, 1991; Gilbert, et al., 1998; Justi \& Gilbert, 2002; Schwartz \& Lederman, 2008). Models cannot be completely accurate and are almost always tentative, in the sense that they are open to further revision and development (Crawford \& Cullin, 2004). In addition, scientists can hold more than one model for the same phenomenon depending on the context, on the purpose of the scientific research and on the perspective of the scientist. An expressed model is available for other scientists to discuss and to reflect upon. Therefore, scientific enterprise can be conceptualised as a process of comparing and testing competing models (Giere, 1990; Hestenes, 1987; 1997; Penner, 2001). 


\section{Students' epistemological understanding of models and the process of modelling}

Grosslight et al. (1991) interviewed middle and high school science students and experts' to assess their epistemological understanding of models and modelling in science. The questions aimed to address the following dimensions: kinds of models, purpose of models, designing and creating models, multiple models for the same phenomenon, and changing models. Three general levels of understanding emerged from the interviews: Level 1, which corresponds to a 'naïve realist' epistemology of models and modelling, entails the notion that models are simple copies of reality. Students who hold a Level 1 understanding do not make an ontological distinction between the observable objects and events of the material world and the entities that are created and defined for the purpose of building scientific models. At Level 2, students do realise that there is a specific, explicit purpose that determines the way the model is constructed. These students acknowledge that the modeller makes deliberate choices on how to achieve this purpose. According to a Level 2 understanding, the model does not need to reflect all properties of the real-world phenomenon being modelled. Finally, the experts held a Level 3 understanding, in that they conceived that models are constructed in service of developing and testing ideas rather than replicating reality; that the modeller takes an active role in constructing the model; and that models can be manipulated and subjected to tests in the service of informing ideas and generating predictions. The main characteristic to distinguish Level 2 from Level 3 is that the main focus of a Level 2 conception is still on the model and the reality modelled and not on the ideas portrayed.

Employing this characterisation, Grosslight et al. (1991) found that the majority (67\%) of middle school students were at level 1, 12\% were at level 2, and $18 \%$ reached an understanding that fell in between the levels 1 and 2 (i.e. mixed level). Of the high school students, only $23 \%$ had level 1 scores and the rest were split evenly between the mixed level 
$1 / 2(36 \%)$ and level $2(36 \%)$. None of the students in Grosslight et al.'s (1991) study reached

Level 3.

The general trend in these findings has been confirmed in several other studies (cf., Lederman, 1992). For instance, Treagust et al. (2002) found that a great deal of secondary science students did not understand how models are used in the development of scientific ideas. Most students valued the visual aspect of scientific models, but were not able to reason beyond the descriptive nature of models (cf. Barowy \& Roberts, 1999). However, counter to the findings from Grosslight et al.'s study (1991), Treagust et al. (2002) found that students, in general, do have an understanding that it is possible to have multiple models for the same phenomenon and that each model displays a particular perspective or emphasis. Schwarz \& White (2005) found that students' epistemological understanding regarding the creation, evaluation and revision of models was moderate (cf. Spitulnik, Krajcik, \& Soloway, 1999). This was still the case after students had worked through a curriculum in which they learned about the nature of scientific models and engaged in modelling activities. When they were asked about the relative value of alternative models, for instance, students responded that all models are of equal value. In addition, more than half of the students agreed that model revision occurs when there is new information or evidence available, or when the model is simply wrong.

However, the approach taken by Grosslight et al. (1991) focuses on an epistemology of science at a rather abstract level. The validity of this approach has been questioned, because students epistemological ideas are likely to be context-bound (e.g. Elby \& Hammer, 2001; Hofer \& Pintrich, 1997; Hogan, 2000; Paulsen \& Wells, 1998). As a consequence, in specific contexts, students may entertain advanced epistemologies without being able to articulate the underlying viewpoints in general. Moreover, a student could provide 'high-level' answers on a generic questionnaire, based on hearsay only. Finally, different contexts make different 
demands upon students, and some forms of epistemological understanding may be more beneficial to learning in some contexts than in others (Elby \& Hammer, 2001; Hogan, 1998; Leach, Millar, Ryder, \& Séré, 2000; Schwarz, 2002b). Therefore, while maintaining the dimensions and levels as defined by Grosslight et al. (1991), a more legitimate assessment could be achieved if the questions are situated in the concrete problem context at hand. Studies relating students' epistemological understanding of models and the process of modelling with their cognitive processing

Although many of the studies cited above, conclude suggesting that students' poor epistemological understanding might restrict their cognitive processing during modelling, there is little direct evidence for such a relation. Several authors have provided evidence for a relation between students' epistemological understanding and their performance on general inquiry activities (e.g. Buffler, Allie, Lubben, \& Campbell, 2001; Gomes, Borges, \& Justi, 2008; Hammer, 1994; Millar, Lubben, Gott, \& Duggan, 1994; Purdie, Hattie, \& Douglas, 1996; Ryder \& Leach, 1999; Schauble, Glaser, Raghavan, \& Reiner, 1991; Schommer, 1990; Songer \& Linn, 1991). However, as argued above, such findings cannot straightforwardly be generalised across contexts.

Within the field of scientific modelling, there have been only a few studies that attempted to relate students' epistemological understanding to their cognitive processing during modelling. First, Schwarz \& White (2005) evaluated a model-centred method to science education, where they taught middle school students on the nature of scientific models and in which students were engaged in the process of modelling. Based on correlational results, including significant correlations between pre-test epistemology scores and post-test scores on an applied physics test, Schwarz \& White (2005) conclude that a better epistemological understanding may significantly contribute to the acquisition of modelling skills and physics knowledge. Correspondingly, Gobert \& Discenna (1997) found that students who hold a 
sophisticated epistemology of models were able to make significantly more inferences on the basis of their models compared to those who hold a naïve epistemological understanding. However, both studies were focused at learning outcomes and did not directly observe the students' cognitive processes during their modelling task.

Talsma (2000) took another approach, by inferring students' epistemological and strategic understanding (i.e. understanding of students related to how they define, plan, implement and evaluate modelling activities) from the notes they had taken during the construction of computer models in the domain of ecosystems. She found that most students constructed models with a specific purpose focused on reality (i.e. Level 2). In evaluating their models, students generally commented that they would add more variables, reflecting an epistemological understanding that is characterised by the addition of new information (i.e. Level 2). Only few students showed a focus on ideas or the testing of possible theories (i.e. Level 3). Regarding students' strategic understanding, Talsma (2000) found that many students were sufficiently able to define the phenomenon to be addressed by their models. In addition, all students constructed models that could be executed on the computer, but often included redundant relations and variables. However, given that Talsma (2000) inferred students' strategic and epistemological understandings from their modelling processes, this approach is not suitable to test the relation between understanding to process. In fact, none of the above-mentioned studies focused on whether and how students' epistemological understanding is related to their cognitive processing during modelling.

To perform well on an complex and open task, like a computer modelling task, students need to engage in Deep cognitive processing, as described in the work of Marton \& Säljö (1976; 1997), Ramsden (1992), and Entwistle (1981; 1988; 2001), involves active learning processes, such as relating ideas, looking for patterns and principles and attempting to integrate new information with prior knowledge and experience. Surface cognitive 
processing, in contrast, entails processes without much reflecting and involves treating the learning material as more or less unrelated bits of information. Surface processing does not imply elaboration of the learning material and leads to more restricted learning processes. Accordingly, it can be expected that high scores on epistemological understanding may be related to the employment of more deep processes and fewer surface processes (cf. Kardash \& Howell, 2000; Windschnitl \& André, 1998).

\title{
The current study
}

The central aim of the present study is to investigate the relation between students' cognitive processing during a modelling task and their epistemological understanding of the task at hand. In particular, we expect that a more sophisticated epistemology of models and modelling will be associated with more deep cognitive processes and less surface cognitive processes during modelling. Therefore, our main research question is:

What is the relation between the level of students' epistemological understanding of models and the process of modelling and the level of their cognitive processing during $\underline{\text { modelling? }}$

\author{
Method \\ Participants \\ The study involved twenty-six students from eleventh-grade pre-university education, with a \\ major in science. Their science teachers had confirmed that the students had no prior \\ experience with dynamic modelling or the domain of mechanics. Students' age ranged \\ between 16-18 years. During the modelling task, participants worked in pairs, which were \\ composed by having the students choose their own partners from within a group of familiar \\ students.
}




\section{Modelling task}

Participants were presented with a task to explore and extend a model of the distance covered by an ice-skater ${ }^{1}$. Since participants had no prior experience with modelling, a completely open modelling task would be too complex for them to be successful within the time constraints of the experiment. Therefore, participants were given an incomplete model as a starting point. Such a model revision task enables the novice modeller to concentrate on trying to comprehend and improve a model without having to start from scratch.

The modelling task was implemented in Powersim ${ }^{\circledR}$ constructor Lite version 2.51, which is freely available for non-commercial use in educational settings (Byrknes \& Myrtveit, 1997). Powersim is a modelling tool based on system dynamics (see Figure 1). Powersim models are built of the five system dynamics model building blocks: Stocks, rates, auxiliaries, constants, and connectors. Stocks represent a quantity that can increase or decrease from some starting value. A rate connected to a stock decides how quickly the quantity in the stock will change. Quantities can be represented either as constants (i.e. fixed values), or as auxiliaries (i.e. calculated from other quantities). Finally, connectors indicate dependencies between model elements. To insert a modelling element, students can drag and drop the icons on the screen they think are relevant for the phenomenon being modelled, creating a qualitative diagram of the phenomenon. While creating this diagram, students can quantify these elements by entering values and formulas. Once the model has been quantified it can be run. When students run their model, Powersim automatically generates the differential equations required to perform calculations. The results of simulations runs over time can be displayed as graphs or tables.

\footnotetext{
${ }^{1}$ Adapted from 'Computerondersteund modelleren natuurkunde: Een sportieve beweging' ['Computer-supported modelling physics: good sports in motion'] (courtesy of Koos Kortland, Kees Hooyman, and Development Group Dynamic Modelling, University of Utrecht). Available from:

http://www.cdbeta.uu.nl/vo/onderwijsmateriaal.php?id=10
} 
[Insert figure 1 about here]

The modelling task was presented in a cover story in which a scientist attempted to construct a model of this phenomenon. Participants were provided with measurements that were obtained by the scientist, which they could use to test the model. The empirical data was presented in two graphs, one for the distance covered by the skater (see upper right hand side of Figure 1) and one graph for the velocity of the skater (lower right-hand side of Figure 1). Participants' task was to extend their model in such a way in that it would provide a good match with the data. Successful completion of the task would require the identification of two friction forces and of a feedback loop which runs from velocity to air resistance. This feedback implies that a skater at a higher velocity experiences more air friction, which consequently leads to a more rapid decrease in velocity.

\section{Data collection}

\section{Level of epistemological understanding}

An open-ended questionnaire was developed to measure students epistemological understanding of the nature of models, the purpose of models, the design and revision of models, and the evaluation of models. The questionnaire (see Appendix A) was patterned after the work of Grosslight et al. (1991). The questionnaire was presented directly after the modelling task, which served as a context to frame the questions. Answers of students to the items in our questionnaire were first analysed qualitatively to examine whether they would fit in one of the four following dimensions:

1. Nature of models: How to define a model?

2. Purposes of models: What is the purpose of a model and modelling?

3. Design and revision of models: How are models constructed and when and how are they revised? 
4. Evaluation of models: How are models evaluated and what are the criteria for the evaluation of a model?

The answers of every individual student were first interpreted in terms of the dimensions mentioned above. Next, it was investigated within every dimension whether the provided answers could be categorised according to level of sophistication. Each student was given a level of epistemological understanding rating (high, moderate, low) for each of the four dimensions, employing the three levels articulated in the studies of Carey \& Smith (1993) and Grosslight et al. (1991; see Appendix B for scoring and examples). Two independent judges each scored half of the data. Interrater reliability was considered to be acceptable for the present purposes $(n=52$, Cohen's kappa $=0.70)($ Heuvelmans $\&$ Sanders, 1993).

\section{Cognitive processing}

Throughout the modelling task, both students' onscreen actions as well as the verbal communication between them were recorded using the program Lotus ScreenCam ${ }^{\mathrm{TM}}$. Verbal protocols were obtained by transcribing these recordings. Students' cognitive processing was measured by analyzing these transcripts employing the protocol analysis scheme of Sins et al. (2005). Although students' verbalizations and behaviours do not fully reveal their covert cognitive processes, the assumption of the present methodology is that the nature of students' discourse and of their actions affords valid indications of the level of their cognitive processing (cf. Hogan \& Thomas, 2001). The transcripts were scored employing two scoring rubrics that were taken from the scheme of Sins et al. $(2005)^{2}$ : a) students' reasoning processes during modelling and b) type of reference made by students during reasoning (see Appendix B for coding scheme).

\footnotetext{
${ }^{2}$ In addition to these two categories, the protocol analysis scheme of Sins et al. (2005) also includes the category: 'topic focus of students' reasoning'. We did not include this code in the present analyses, since reasoning processes coupled with the type of reference students make during process-episodes provide sufficient information concerning students' level of cognitive processing.
} 
Reasoning processes such as analysing or explaining mostly involve several turns by both partners in a dyad (Brickell, Ferry, \& Harper, 2002). Therefore, the unit of analysis was determined to be at the episode level, an episode being defined as a period of coherent continuous talk on a single issue. Episodes were segmented on the basis of following noncontent criteria (cf. Chi, 1997). A new episode would start:

- Following each run of the students' model.

- Following each interval of more than $15 \mathrm{~s}$ during which nothing is said.

- At the start and at the end of each experimenter intervention.

- The maximum length for a segment is $1 \mathrm{~min}$. If a segment lasts longer, the segment will be more closely analysed in order to see whether segmentation is possible on the basis of changes in reasoning process or changes in focus (often signalled by words as: “Okay ..." or "Now ....").

Reasoning episodes in which students are elaborating on the modelling task and connect to their knowledge, which can be either gained from the task at hand or prior knowledge, were designated as deep cognitive processing. Episodes in which students posit unelaborated statements without reference to available knowledge were labelled as surface cognitive processing. The remaining episodes were scored indifferent, and excluded for the purpose of this analysis. The following specific codes were operationalised as indications of deep processing:

- Evaluating with reference to knowledge

- Explaining with reference to knowledge

- Quantifying with reference to knowledge

- Inductive reasoning with reference to knowledge

- Analyzing with reference to knowledge

The following codes indicated surface processing: 
- Evaluating with no reference to knowledge

- Quantifying with no reference to knowledge

- Analyzing with no reference knowledge

\section{Since the relation between epistemological understanding and cognitive processing was} scored at the individual level, while students' cognitive processing had to assessed in a collaborative setting, we counted the numbers of utterances that individual students contributed to the different types of process episodes as an indicator of individual processing. Because the total numbers of utterances differ across individuals, reporting frequencies would result in a skewed image. Therefore, for each individual student within a dyad, the amounts of deep and surface processes were expressed as proportion of total number of utterances by that student.

Interrater reliability for these codes was determined by comparing the ratings of two independent judges $(n=212$; Cohen's kappa $=0.75)$. This interrater reliability can be regarded as satisfactory for the present purposes (Heuvelmans \& Sanders, 1993).

\section{Procedure}

In order to get acquainted with system dynamics modelling in Powersim, each student individually worked through a tutorial ${ }^{3}$. In this tutorial, students were presented with an example model of a water tank. This system provides a very simple example to illustrate fundamental aspects of modelling and the behaviour of dynamic systems is that of a water tank containing a faucet and a drain. The volume of water in the water tank is represented by the stock variable (i.e. reservoir variable), and the flows represent respectively the inflow of water into the water tank through the faucet and the outflow of water from the water tank through a sink. The water tank model, its elements (i.e. variables and relationships between

\footnotetext{
${ }^{3}$ Adapted from: Computerondersteund modelleren: Basishandleiding Powersim [Computer supported modelling: Powersim manual (in Dutch) available from: http://www.cdbeta.uu.nl/vo/onderwijsmateriaal.php?id=17
} 
variables) and how it can be built in Powersim were explained to students in the instruction. Also, students could execute and revise parts of the water tank model in the Powersim environment. The instruction took about one hour. Subsequently, participants were grouped in dyads. Participants were informed that they were going to explore and subsequently revise models working in couples. Next, dyads read the modelling task and were presented with the initial model version and with the data. Dyads were asked to collaboratively revise the model for approximately one and a half hour. Finally, students completed the epistemology questionnaire.

\section{Results}

\section{Cognitive processing}

Table 1 shows the mean percentages with examples of the deep and surface cognitive processes students employed during modelling. It becomes apparent from Table 1 that, on average, the students employed much more surface processes compared to deep processes. Most surface processes involve students' quantifying their model without referring to knowledge, whereas for deep processes, the process that is employed the most is students' quantifying with reference to knowledge. The processes explaining with reference to knowledge and analyzing with reference to knowledge, occur only rarely (see Table 1).

[Insert Table 1 about here]

\section{Level of epistemological understanding}

Based on their answers on the questionnaire, students got graded as Level 1, 2 or 3 on each of the four dimensions of epistemological understanding. As shown in Table 2, on three of the four dimensions more than half of the students reached a Level 2 epistemological understanding. On the dimension Purposes of models $46 \%$ of the students reached Level 2 and $42 \%$ of the students reached a Level 3 epistemological understanding. Internal 
consistency for epistemological understanding on these four categories showed to be acceptable $(\underline{\alpha}=0.70)$. Consequently, a students' epistemological understanding of models and modelling could be expressed in a single score as the mean of four subscores. Over the whole sample of students, the mean score was 2.07 with a standard deviation of 0.41 .

\section{[Insert table 2 about here]}

\section{Relation between epistemological understanding and cognitive processing}

To investigate the extent to which students' epistemological understanding of models and modelling is related to their level of processing, we computed the correlation between both measures, using the non-parametric Spearman rank method. Both the correlations between epistemological understanding and deep processing $(\underline{\mathrm{r}}=0.40, \underline{\mathrm{p}}=0.04)$ and between epistemological understanding and surface processing $(\underline{\mathrm{r}}=-0.51, \underline{\mathrm{p}}=0.008)$ were significant and in the expected directions. Figures 2 and 3 provide the respective scatter plots.

\section{[Insert figure 2 about here] \\ [Insert figure 3 about here]}

To corroborate the quantitative results presented above, we provide an exploratory qualitative analysis of the relationship between students' answers on the epistemology questionnaire, and their reasoning during modelling.

First, we will consider Roel, who expressed a preference for simple models:

'By using very simple models, you may use them for multiple purposes' (Roel; Epistemology score: Level 3, Process of modelling) 
While working on the modelling task, together with Dave, Roel acted in accordance with this view when they were reasoning about how to quantify a feedback loop they had just implemented in their model, making "air friction" dependent on "velocity":

$\mathrm{R}$ The formula for deceleration should be: velocity multiplied by air friction, which should actually be squared

R Actually we could implement that later in our model, but we have to start simple

R Also, we should also take the air density coefficient into consideration

D Yes

$\mathrm{R} \quad$ But we will do that later

(Protocol: Dave and Roel; Process code: Quantify and reference to knowledge)

In this excerpt, Roel correctly identifies the quadratic relation between the "air friction" and "velocity", but nevertheless prefers to start with a simpler formula, in order to keep his model simple from the start.

Next, we will consider Mark, who defined a model as:

'A model approaches reality by means of several assumptions and calculations. A model is built based on various relations, whih are either known or estimated. These are entered in the computer in this case, after which these quantitative relations can be investigated and assumptions tested' (Mark; Epistemology score: Level 3, Nature of models)

This high level epistemological stance on the nature of models is reflected in Mark's contributions while working with Hugo to quantify variables in their model:

M So we have to multiply air friction and velocity, velocity should be 
squared, and frontal surface of the skater

M But those are all things we have to estimate, we do not have any data for this

M It is difficult to estimate these, since they are all constants actually

$\mathrm{H} \quad$ What do you think that the frontal surface of the skater could be?

M We cannot look it up somewhere

(Protocol: Mark and Hugo; Process code: Quantify and reference to knowledge)

In agreement with his view that models are based on assumptions of the modeller, Mark asserts that, if values for variables are not known, they can be estimated based on their prior understanding.

More generally, in the protocols of students with a high epistemological understanding, there is frequent reference to knowledge. This indicates that students consider their own understanding as contributing to the advancement of their model. This is exemplified in the following excerpt taken from the protocol of Dave and Roel:

$\mathrm{R}$ The skater does not skate at a constant velocity, it changes over time

$\mathrm{R} \quad$ He starts at 15 meters per second I think and that is...

D No, but it figures, he stops at a moment, he stops skating and then he slides on and then he goes this fast

D At the beginning he decelerates rapidly and then the deceleration becomes less, you see?

$\mathrm{R} \quad$ Yes, so the friction is higher at the start and becoming less at the end

(Protocol: Dave and Roel; Process code: Reason and reference to knowledge)

By contrast, students who scored low on epistemological understanding tended to focus on the visual aspects of models. As an example consider the way Marije defined a model: 


\author{
'[A model is a] scheme where you can change things and where you can see what the \\ output is if you add or change something' \\ (Marije; Epistemology score: Level 1, Nature of models)
}

Fully in line with this stance, Marije and her partner Lola focused on visual attributes of their model:

L Maybe we have to enter a circle here

M A circle from velocity and...

L I really do not understand this

M But you know, distance is also dependent on deceleration and velocity, otherwise there would be no arrows going to that variable

(Protocol: Marije and Lola; Process code: Analyse and no reference to knowledge)

Denise and Astrid expressed the following epistemological views on respectively the purpose of models and on the process of modelling:

'Models are a collection of measurements'

(Denise; Epistemology score: Level 1, Purpose of modelling)

'Modelling = playing with values and formulas on the computer of the model matches the measured values'

(Astrid; Epistemology score: Level 2, Process of modelling)

Both views are reflected in the way Denise and Astrid go ahead to evaluate the fit between the empirical data and the output generated by their model:

1 D Yes he $\{$ the model graph $\}$ should be somewhat

2 D Yes, the graph is going too far, right?

3 A Yes, but that does not matter that much now

4 D No, we have to make the graph better here

URL: http://mc.manuscriptcentral.com/tsed Email: editor_ijse@hotmail.co.uk 
5 A These values we entered are just too low

6 D Why do we not just change the data?

7 D Look, here he $\{$ the graph $\}$ is just too low, but here it looks

$$
\text { fine }
$$$$
8 \text { A It is just manipulating with numbers! }
$$

(Protocol: Denise and Astrid; Process code: Evaluate and no reference to knowledge)

In this episode both of the epistemological views presented above are enacted: whereas

Denise focuses on the graph in lines 1, 2, 4 and 7 and even conflates empirical data with model output in line 6, is Astrid engaged in fitting the model with the data as exemplified in line 8 .

Overall, students scoring low on epistemological understanding employed mainly surface processes in which reasoning was restricted to the model at hand instead of being focused on attempting to comprehend the phenomenon modelled.

\section{Conclusion and Discussion}

The purpose of the present study was to investigate the relationship between the students' cognitive processing during computer modelling (i.e. deep versus surface processing), and their epistemological understanding. The assessment of epistemological understanding was framed within the task at hand, because students' epistemologies are supposed to be contextbound. We expected that students with a more sophisticated epistemological understanding would engage more in deep processing, whereas students with a poor epistemological understanding would mainly stick to surface processing.

Findings indicate that, on average, students' epistemological understanding of computer models and the process of modelling was about Level 2. In comparison to studies with similar students reported in the literature, the students in our sample seem to hold relatively advanced epistemological viewpoints. An explanation for this finding may be come from the assessment 
being framed in the context of a more or less authentic computer modelling task. By contrast, in the work of both Grosslight et al. (1991) and Treagust et al. (2002) students' epistemological understanding was assessed within the context of a general science curriculum. In Schwarz' and White's (2005) study, there was the context of a concrete modelling task, but this task was highly constrained, in the sense that students were asked to chose among three (or four) computer-modelling rules the one that most closely resembled their own mental model.

With respect to the relation between the students' epistemological understanding of models and the process of modelling and their cognitive processing, we found significant and substantial correlations between epistemological understanding and deep processing (positive), and between epistemological understanding and surface processes (negative).

Exploratory qualitative analysis of protocols of the groups scoring low versus high on epistemological understanding corroborated the quantitative analyses, in that students' epistemological stances were enacted in their reasoning. For instance, the finding that students who are high on epistemology refer to prior knowledge during modelling seemed to be related to the epistemological stance that one's own understanding of the phenomenon is useful in constructing the model. This may indicate that these students conceptualized a model as an idea portrayed, and that in order to improve their model it needs elaborate thinking based on their own understanding. Students expressing poor epistemological understanding of models, in contrast, resorted to mainly employing surface processes in which they focused on visual aspects of their model, were engaged in model fitting behaviour and even confused model output with empirical data. The protocols of these students reflected an epistemological stance which regards models as the reality being portrayed, instead of as tools to comprehend the phenomenon modelled. 
As a limitation of the study, it should first be noted that students' epistemological understanding was assessed after the task, in order to get a more valid and contextualised portrayal of their ideas. The obvious disadvantage would be that the students might have changed their epistemological understanding as a consequence of working on the task, and that the causal direction of the relation we found could be either way. However, as we had no specific epistemological instruction, and as the duration of the task was quite limited, we regard it more likely that students' epistemological understanding affected their processing, than the other way round. In a follow up study the assessment of epistemological understanding could precede the assessment of cognitive processing, if we would introduce an extra modelling task preceding the current one, to provide a proper context for the epistemology assessment.

Moreover, students' epistemological understanding was assessed in an individual setting, while cognitive processing was assessed in a collaborative setting, were students had selected their own partners. In this self-selected collaborative setting, a students' contributions will also be influenced by their partner's contributions. Nevertheless, students' contributions to either deep or surface process episodes provide insight in their abilities (cf. Hogan, 1999; Hogan \& Thomas, 2001). For instance, students who are more capable to elaborate upon their model compared to their partners, are also likely to contribute more to process-episodes that are scored as deep. In this study, the focus was on the relation between individual understanding and individual performance, and working in dyads was the way to elicit the cognitive processes we were interested in. It has been documented that the composition of dyads in terms of equal ability versus mixed ability learners may lead to differential learning effects (e.g. Gijlers \& de Jong, 2005; Webb, 1991; Webb, Welner, \& Zuniga, 2001). From an educational perspective, it would be worthwhile to investigate whether similar effects occur if partners vary with respect to their epistemological understanding. 


\section{References}

Barowy, W., \& Roberts, N. (1999). Modelling as an inquiry activity in school science: What's the point? In N. Roberts, W. Feurzeig, \& B. Hunter (Eds.), Modelling and Simulation in Science and Mathematics Education (pp. 197-225). Berlin: Springer Verlag.

Bliss, J. (1994). From mental models to modelling. In H. Mellar, J. Bliss, R. Boohan, J. Ogborn, \& C. Thompsett (Eds.), Learning with Artificial Worlds: Computer Based Modelling in the Curriculum (pp. 27-33). London: The Falmer Press.

Buffler, A., Allie, S., Lubben, F., \& Campbell, B. (2001). The development of first year physics students' ideas about measurement in terms of point and set paradigms. International Journal of Science Education, 23(11), 1137-1156.

Byrknes, A. \& Myrtveit, M. (1997). Learning dynamic modelling. Goteborg, Sweden: Powersim Press.

Carey, S. \& Smith, C. (1993). On understanding the nature of scientific knowledge. Educational Psychologist, 28(3), 235-251.

Chi, M.T.H. (1997). Quantifying qualitative analyses of verbal data: A practical guide. The Journal of the Learning Sciences, 6(3), 271-315.

Coon, T. (1988). Using STELLA simulation software in life science education. Computers in Life Science Education, 5(9), 56-71.

Craik, F.I. \& Lockhart, R.S. (1972). Levels of processing: A framework for memory research. Journal of Verbal Learning and Verbal Behaviour, 11(6), 971-684.

Crawford, B.A. \& Cullin, M.J. (2004). Supporting prospective teachers' conceptions of modelling in science. International Journal of Science Education, 26(11), 1379-1401.

Doyle, J.K. \& Ford, D.N. (1998). Mental models concepts for system dynamics research. System Dynamics Review, 14(1), 3-29. 
Driel, J.H. van \& Verloop, N. (1999). Teachers' knowledge of models and modelling in science. International Journal of Science Education, 21(11), 1141-1153.

Driver, R., Leach, J., Millar, R., \& Scott, P. (1996). Young People's Images of Science. Buckingham, UK: Open University Press.

Elby, A. \& Hammer, D. (2001). On the substance of a sophisticated epistemology. Science Education, 85(5), 554-567.

Entwistle, N. (1988). Styles of Learning and Teaching. David Fulton: London.

Entwistle, N. (2001). Styles of learning and approaches to studying in higher education. Learning Styles in Higher Education, 30(5/6), 593-602.

Giere, R.N. (1990). Explaining science. Chicago: University of Chicago Press.

Gijlers, H. \& Jong, T. de (2005). The relation between prior knowledge and students' collaborative discovery learning processes. Journal of Research in Science Teaching, 42(3), 264-282.

Gilbert, J.K., Boulter, C., Rutherford, M. (1998). Models in Explanations Part 1: Horses for Courses? International Journal of Science Education, 20(1), 83-97.

Gilbert, S.W. (1991). Model building and a definition of science. Journal of Research in Science Teaching, 28, 73-79.

Gobert, J. \& Discenna, J. (1997). The Relationship between Students' Epistemologies and Model-based Reasoning. Paper presented at the annual meeting of the American Educational Research Association, Chicago, IL.

Gobert, J., Snyder, J., \& Houghton, C. (2002). The Influence of Students' Understanding of Models on Model-based Reasoning. Paper presented at the annual meeting of the American Educational Research Association, New Orleans, LA. 


\section{Gomes, A. D. T., Borges, A. T., \& Justi, R. (2008). Students' Performance in Investigative} Activity and Their Understanding of Activity Aims. International Journal of Science Education, 30, 109-135.

Grosslight, L., Unger, C., Jay, E., \& Smith, C.L. (1991). Understanding models and their use in science: Conceptions of middle and high school students and experts. Journal of Research in Science Teaching, 28(9), 799-822.

Hammer, D. (1994). Epistemological beliefs in introductory physics. Cognition and Instruction, 12(2), 151-183.

Hammer, D. \& Elby, A. (2002). On the form of a personal epistemology. In B. K. Hofer, \& P. R. Pintrich (Ed.), Personal Epistemology: The Psychology of Beliefs about Knowledge and Knowing (pp. 169-190). Mahwah, N.J.: Lawrence Erlbaum.

Hestenes, D. (1987). Toward a modelling theory of physics instruction. American Journal of Physics, 55(5), 440-454.

Hestenes, D. (1997). Modelling methodology for physics teachers. In E. Redish \& J. Rigden (Eds.), The Changing Role of the Physics Department in Modern Universities, Proceedings of ICUPE (pp. 935-957). The American Institute of Physics.

Heuvelmans, A.P.J.M. \& Sanders, P.F. (1993). Beoordelaarsoverstemming [Inter-judgement reliability measurement]. In T.J.H.M. Eggen \& P.F. Sanders (Eds.), Psychometrie in de Praktijk [Psychometrics in Practice] (pp. 443-469). Arnhem, The Netherlands: CITO.

Hofer, B. K. (2001). Personal epistemology research: Implications for learning and teaching. Educational Psychology Review, 13, 353-382.

Hofer, B. K., \& Pintrich, P. R. (1997). The development of epistemological theories: Beliefs about knowledge and knowing and their relation to learning. Review of Educational Research, 67, 88-140. 
Hogan, K. (1999). Relating Students' Personal Frameworks for Science Learning to Their Cognition in Collaborative Contexts. Science Education, 83(1), 1-32.

Hogan, K. (2000). Exploring a process view of students' knowledge about the nature of science. Science Education, 84, 51-70.

Hogan, K. \& Thomas, D. (2001). Cognitive comparisons of students' systems modelling in ecology. Journal of Science Education and Technology, 10(4), 319-345.

Jackson, S.L., Stratford, S.J., Krajcik, J., \& Soloway, E. (1996). Making dynamic modelling accessible to pre-college science students. Interactive Learning Environments, 4(3), 233257.

Jonassen, D.H., Strobel, J., \& Gottdenker, J. (2005). Modelling for meaningful learning. In Learning sciences and Technologies Group (Ed.), Engaged Learning with Emerging Technologies (pp. 1-28). Dordrecht, NL: Springer Verlag.

Justi, R.S. \& Gilbert, J.K. (2002). Modelling, teachers' views on the nature of modelling, and implications for the education of modellers. International Journal of Science Education, 24(4), 369-387.

Kardash, C.M. \& Howell, K.L. (2000). Effects of epistemological beliefs and topic-specific beliefs on undergraduates' cognitive and strategic processing of dual-positional text. Journal of Educational Psychology, 92(3), 524-535.

Leach, J., Millar, R., Ryder, J., \& Séré, M.G. (2000). Epistemological understanding in science learning: The consistency of representations across contexts. Learning and Instruction, 10, 497-527.

Lederman, N.G. (1992). Students' and teachers' conceptions of the nature of science: A review of the research. Journal of Research in Science Teaching, 26(9), 771-783.

Marton, F. \& Säljö, R. (1976). On qualitative differences in learning. I - outcome and process. British Journal of Educational Psychology, 46, 4-11. 
Marton, F. \& Säljö, R. (1997). Approaches to learning. In F. Marton, D.J. Hounsell, \& N.J. Entwistle (Eds.), The Experience of Learning, $2^{\text {nd }}$ Edition (pp. 39-58). Edinburgh: Scottish Academic Press.

Millar, R., Lubben, F., Gott, R., \& Duggan, S. (1994). Investigating in the school science laboratory: Conceptual and procedural knowledge and their influence on performance. Research Papers in Education, 9(2), 207-248.

Paulsen, M. B. \& Wells, C. T. (1998). Domain differences in the epistemological beliefs of college students. Research in Higher Education, 39, 365-384.

Penner, D. E. (2001). Cognition, computers, and synthetic science: Building knowledge and meaning through modelling. Review of Research in Education, 25, 1-36.

Purdie, N., Hattie, J. and Douglas, G. (1996) Student conceptions of learning and their use of self-regulated learning strategies: a cross cultural comparison. Journal of Educational Psychology, 88(1), 87-100.

Raghavan, K., Sartoris, M.L \& Glaser, R. (1998). Impact of the MARS curriculum: The mass unit. Science Education, 82, 53-91.

Ramsden, P. (1992). Learning to Teach in Higher Education. Routledge: London.

Roth, W. \& Roychoudhury, A. (1994). Physics students' epistemologies and views about knowing and learning. Journal of Research in Science Teaching, 31(1), 5-30.

Ryder, J. \& Leach, J. (1999). University science students' experiences of investigative project work and their images of science. International Journal of Science Education, 21(9), 945956.

Sandoval, W.A. (2003). The inquiry paradox: Why doing science doesn't necessarily change ideas about science. In C.P. Constantinou \& Z.C. Zacharia (Eds.), Proceedings of the Sixth International Computer-Based Learning in Science Conference (pp. 825-834). Nicosia, Cyprus. 
Schauble, L., Glaser, R., Raghavan, K., \& Reiner, M. (1991). Causal models and experimentation strategies in scientific reasoning. The Journal of the Learning Sciences, 1(2), 201-238.

Schecker, H.P. (1993). Learning physics by making models. Physics Education, 28, 102-106. Schommer, M. (1990). Effects of beliefs about the nature of knowledge on comprehension. Journal of Educational Psychology, 82(3), 498-504.

Schwarz, C.V. (2002a). Using Model-centred Science Instruction to foster Students' Epistemologies in Learning with Models. Paper presented at the annual meeting of the American Educational Research Association, New Orleans, LA.

Schwarz, C.V. (2002b). The role of epistemic forms and games: Perspectives on the role of meta-modelling knowledge in learning with models. In P. Bell, R. Stevens \& T Satwicz (Eds.), Keeping Learning Complex: The proceedings of the Fifth International Conference of the Learning Sciences (ICLS) (pp. 414-420). Mahwah, NJ: Erlbaum.

Schwarz, C.V. \& White, B.Y. (2005). Metamodelling knowledge: Developing students' understanding of scientific modelling. Cognition and Instruction, 23(2), 165-205.

Schwartz, R., \& Lederman, N. (2008). What Scientists Say: Scientists' views of nature of science and relation to science context. International Journal of Science Education, 30, $727-771$.

Sins, P.H.M., Joolingen, W.R. van, Savelsbergh, E.R., \& Hout-Wolters, B.H.A.M. van (2008). Motivation and performance within a collaborative computer-based modelling task: Relations between students' achievement goal orientation, self-efficacy, cognitive processing, and achievement. Contemporary Educational Psychology, 33, 58-77.

Sins, P.H.M., Savelsbergh, E.R., Joolingen, W.R. van (2005). The difficult process of scientific modelling: An analysis of novices' reasoning during computer-based modelling. International Journal of Science Education, 27(14), 1695-1721. 
Songer, N.B. \& Linn, M.C. (1991). How do students' views of science influence knowledge integration? Journal of Research in Science Teaching, 28(9), 761-784.

Spector, J.M. (2000). System dynamics and interactive learning environments: Lessons learned and implications for the future. Simulation \& Gaming, 31(4), 528-535.

Spector, J. M., \& Davidsen, P. I. (1997). Creating engaging courseware using system dynamics. Computers in Human Behaviour, 13(2), 127-155.

Spitulnik, M.W., Krajcik, J., \& Soloway, E. (1999). Construction of models to promote scientific understanding. In N. Roberts, W. Feurzeig, \& B. Hunter (Eds.), Modelling and Simulation in Science and Mathematics Education (pp. 71-94). Berlin: Springer Verlag.

Stratford, S.J. (1997). A review of computer-based model research in pre-college science classrooms. Journal of Computers in Mathematics and Science Teaching, 16(1), 3-23.

Talsma, V.L. (2000). Scientific understandings revealed by students' computer models of a stream: A trickle or a flood? In B. Fishman \& S. O’Conner-Divelbiss (Eds.), Fourth International Conference of the Learning Sciences (pp. 98-105). Mahwah, NJ: Erlbaum.

Treagust, D.F., Chittleborough, G., \& Mamiala, T.L. (2002). Students' understanding of the role of scientific models in learning science. International Journal of Science Education, 24(4), 357-368.

Valanides, N. \& Angeli, C. (2005). Effects of instruction on changes in epistemological beliefs. Contemporary Educational Psychology, 30, 314-330.

Verhoeff, R. P., Waarlo, A. J., \& Boersma, K. T. (2008). Systems Modelling and the Development of Coherent Understanding of Cell Biology. International Journal of Science Education, 30, 543-568.

Webb, N. M. (1991). Task related verbal interaction and mathematics learning in small groups. Journal for Research in Mathematics Education, 22, 366-389. 
Webb, N.M., Welner, K., \& Zuniga, S. (2001). Short circuits or superconductors? The effects of group composition on high-ability students' science assessment performance. American Educational Research Journal, 39, 943-989.

White, B. \& Frederiksen, J. (1998). Inquiry, modelling, and metacognition: Making science accessible to all students. Cognition and Instruction, 16(1), 3-117.

Wild, M. (1996). Mental models and computer modelling. Journal of Computer Assisted Reasoning, 12(1), 10-21.

Windschitl, M. \& André, T. (1998). Using computer simulations to enhance conceptual change: The roles of constructivist instruction and student epistemological beliefs. Journal of Research in Science Teaching, 35(2), 145-160.

Zaraza, R. \& Fisher, D.M. (1999). Training system modellers: The NSF CC-STADUS and CC-SUSTAIN projects. In N. Roberts, W. Feurzeig, \& B. Hunter (Eds.), Modelling and Simulation in Science and Mathematics Education (pp. 38-69). Berlin: Springer Verlag. 


\section{Appendix A}

In the next statements we ask you for your view on models and modelling (for example the modelling of friction forces). At every statement you have to indicate whether you agree or disagree with this statement and provide also a short explanation of why you agree or disagree. At some points, you will be presented with an open question, try to provide a clear answer.

1. How do you define a model?

Try to mention everything you can think of when you hear the words 'model' and 'modelling'. Use whole sentences in your answer.

2. Why are models used in science?

3. The model of the scientist in the assignment is wrong Agree/ Disagree, because:

4. Only a small part of reality can be described with this model Agree/ Disagree, because:

5. How do you decide if a model is correct?

6. Scientist should test their model(s) Agree/ Disagree, because:

7. It is impossible to decide which model is the best Agree/ Disagree, because:

8. The scientist in the assignment has to perform more measurements/more experiments in order to construct a better model

Agree/ Disagree, because: 
9. Another scientist (Dr. Schintaler) thinks there is no way to decide which model can describe the given data the best. What do you think?

10. Models are useful in order to better understand phenomena in physics (for example, friction forces or resonance) Agree/ Disagree, because: 

draws on assumptions, is a theory of reality. Students view a model as a depiction of an idea of a researcher.
3. Students acknowledge that a model

\section{Examples}

1. Students view a model as a creation of an 'A model is created by means of the data you have measured' object on the basis of data

Students view a model as a (vague) scheme, concept map or drawing of variables. Students focus on visual aspects of models

2. Students view a model as a (simplistic) representation of reality. Students acknowledge that a model represents something else (i.e. reality)

'[A model is] an overview of a situation where a lot of things influence other things'

'[A model is a] scheme where you can change things and where you can see what the output is if you add or change something'

'With a model you can represent reality'

'A model is a simplified representation of reality in which you can make estimates'

Students view a model as a simulation

'[A model is] a simulation of reality'

(i.e. representation of reality), formula, or as a computational tool. The concern is with how the model works.

'You can simulate different things, such as kinetics, heating of objects, etc.'

'A model is an extended formula with which you can predict measurements'

'By employing several variables and formulas, we can build a simulation of a particular situation or event'

'A model is an image of reality, measurements can be explained with a model $[\ldots]$ everything is set up from a theoretical and fundamental (and simplistic) basis'

\section{Purposes of models}

\section{Level Description Examples}

1. Students think models are used to '[A model is used] to simulate, so that you no longer have to measure measure things, find out answers, collect things'

data (students conflate data with model output)

'In science models are used to better notice and discover things'

2. Students view models to be of use for

'Models are used to gain a better insight into difficult and complex issues' showing how something works (i.e. provide an overview of a phenomenon) A model quickly provides relationships between different variables' or to show dependencies between variables 
Students think models are useful to make research more efficient or to analyse data
'[Models are used] to conduct efficient research. You can easily add relationships and change variables'

'Models can be used for the analysis of measurements'

'[Models are used to] make predictions of particular scientific processes'

'[Models are used to] make predictions of what happens when you change something in the design of an object/ apparatus' making predictions about a phenomenon (in service of improving the design of an artefact)

\section{Process of Modelling}

\section{Level Description Examples}

1. Students view model construction/ revision simply as building/ revising a model

2. Students define model revision as model-fitting

Students view model construction/ revision as changing or adding variables or relations to a model

Students view modelling as a process of specifying variables (and monitoring the output of their model)

Students view modelling as a process of simulating a phenomenon

3. Students try to keep their model as simple as possible in order to obtain more predictive validity (i.e. simplistic elegance in constructing a model)

Students think that model revision occurs by rethinking one's data and their implication as well as the purpose of the models
'From a situation you make a model'

'Modelling is to construct and change a model'

'Modelling = playing with values and formulas until the output of the model matches the measured values'

'[Modelling is] changing values and formulas on the computer with more accurateness'

'[Modelling is] deciding which factors are involved'

'Modelling is when you add several important factors to predict something'

'[Modelling is] putting formulas together, by which you enable more factors to play a role in the output'

'[Modelling is] examining what the effect is of changing a variable'

'[Modelling is] to simulate a scientific phenomena'

'By using very simple models, you may use them for multiple goals'

'If the researcher uses new measurement methods, he may come to other conclusions regarding his/ her model and may ultimately change his/ here model' 


\section{Evaluation of models}

\section{Level Description Examples}

1. Students report that they vaguely check 'If the model is build logically and based upon controllable facts'

their model (at face value or compare 'If the model is reliable' the model with reality)

2. Students think that models are evaluated 'If it matches the measurements' by comparing it with empirical data

'You have to compare the data from the model with data you have obtained and the one that fits the best is correct'

Students view model evaluation as 'Checking whether you have taken all factors into account' examining whether all relevant variables are included in the model

3. Students report that they evaluate

'You have to ask other scientists for their opinion' models by comparing it with data obtained from multiple measurements or with the opinion of other researchers 
2

3

\section{Type of reasoning process}

\section{Evaluate}

Students positively/ negatively evaluate an element(s) in relation to their model. Students make a (elaborate) value judgment on a modelling element

$\underline{\text { Explain }}$

Students explain to each other how elements within their model work or why they were included, etc. An explanation must be preceded by a clear-cut question of one of the students

Quantify

Students talk about quantifying or specifying a quantity or relation within their model

Inductive Reasoning

Students elaborate upon/ about elements within or with respect to their model (involves mainly qualitative reasoning)

$\underline{\text { Analyse }}$

Students talk about/ interpret modelling elements without further elaboration. Or identify factors that may be relevant/ included in their model without further elaboration (i.e. factors are uttered by the students without further discussion)

\section{Other processes}
$\underline{\text { Read }}$
Students read or paraphrase
Off task (no further coding)
Students talk about subjects unrelated to the modelling task

\section{Type of reference}

\section{None}

Physics knowledge

Mathematics knowledge

Experiential knowledge
No reference to model components or knowledge

Use of terminology, concepts (i.e. units, quantities), formula's common in physics

Use of terminology, concepts, formula's common in mathematics

Knowledge from everyday experience 


\section{Table 1.}

Mean percentages (with standard deviations in parentheses) and examples of process episodes (i.e. deep versus surface cognitive processes)

\begin{tabular}{llr}
\hline $\begin{array}{l}\text { Students' cognitive } \\
\text { processing }\end{array}$ & Examples & Mean (SD) \\
\hline
\end{tabular}

\section{Deep processing}

Evaluate with reference to 'The change of velocity is a particular deceleration that disappears [in the knowledge model], that is correct'

$1.68(2.41)$

Explain with reference to 'Look, the velocity, look, the harder you go, the more the deceleration you knowledge experience, so the velocity slows down, so the deceleration also becomes less'

Quantify with reference to knowledge

'The larger the velocity, the larger the air friction, so therefore we have to multiply [these variables]' reference to knowledge

'Air friction depends on your velocity, if you go faster then your air friction is higher' variable for the ice skater assignment, right?'

\section{Surface processing}

Evaluate with no reference 'This [the graph] is almost correct, look it runs through all [data] points' to knowledge 


\section{Table 2.}

\section{Frequencies and examples of students' responses by level of epistemological understanding}

\begin{tabular}{|c|c|c|}
\hline $\begin{array}{l}\text { Epistemological } \\
\text { understanding }\end{array}$ & Examples & Frequency \\
\hline \multicolumn{3}{|c|}{ 1. Nature of Models } \\
\hline Level 1 & 'A model is created by means of certain data' & 6 \\
\hline Level 2 & 'A model is a simplified representation of reality' & 17 \\
\hline Level 3 & $\begin{array}{l}\text { 'A model predicts events that happen in reality, by using assumptions and } \\
\text { calculations' }\end{array}$ & 3 \\
\hline \multicolumn{3}{|c|}{ 2. Purposes of Models } \\
\hline Level 1 & $\begin{array}{l}\text { 'With a model you do not have to measure everything and you can include } \\
\text { everything in your model' }\end{array}$ & 3 \\
\hline Level 2 & '[A model is used] to obtain a clear overview of which variables are important' & 12 \\
\hline Level 3 & $\begin{array}{l}\text { '[A model is used] to examine and discover relations and to make conclusions from } \\
\text { the predictions made from a model' }\end{array}$ & 11 \\
\hline \multicolumn{3}{|c|}{ 3. Process of Modelling } \\
\hline Level 1 & 'Modelling is to construct a model of something' & 3 \\
\hline Level 2 & 'A model can be improved by adding new variables or relations' & 21 \\
\hline Level 3 & 'By constructing simple models, you can use them for multiple purposes' & 2 \\
\hline \multicolumn{3}{|c|}{ 4. Evaluation of Models } \\
\hline Level 1 & $\begin{array}{l}\text { '[Models are evaluated by] good looking at them and seeing that you did not left } \\
\text { something out' }\end{array}$ & 5 \\
\hline Level 2 & $\begin{array}{l}\text { [A model is correct] if all known factors have been included and when the model } \\
\text { more or less corresponds with the empirical data' }\end{array}$ & 16 \\
\hline Level 3 & $\begin{array}{l}\text { [A model is correct] of its output corresponds with the mean result of multiple (at } \\
\text { least 200) measurements' }\end{array}$ & 5 \\
\hline
\end{tabular}


Figure Captions

Figure 1. Screenshot of a model in Powersim.

Figure 2. Scatter plot of deep processing versus epistemological understanding.

Figure 3. Scatter plot of surface processing versus epistemological understanding. 
Figure 1.

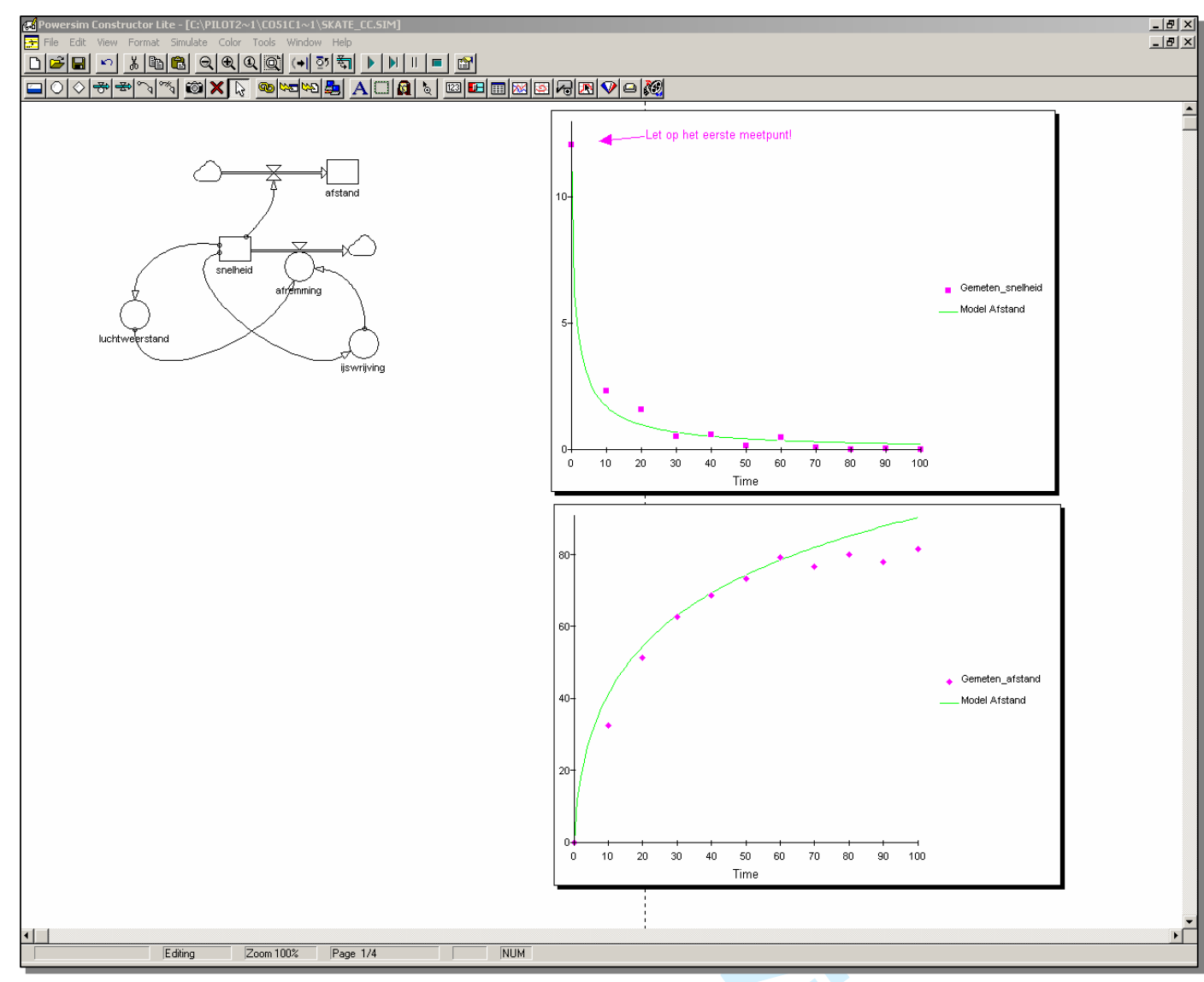




\section{Figure 2.}

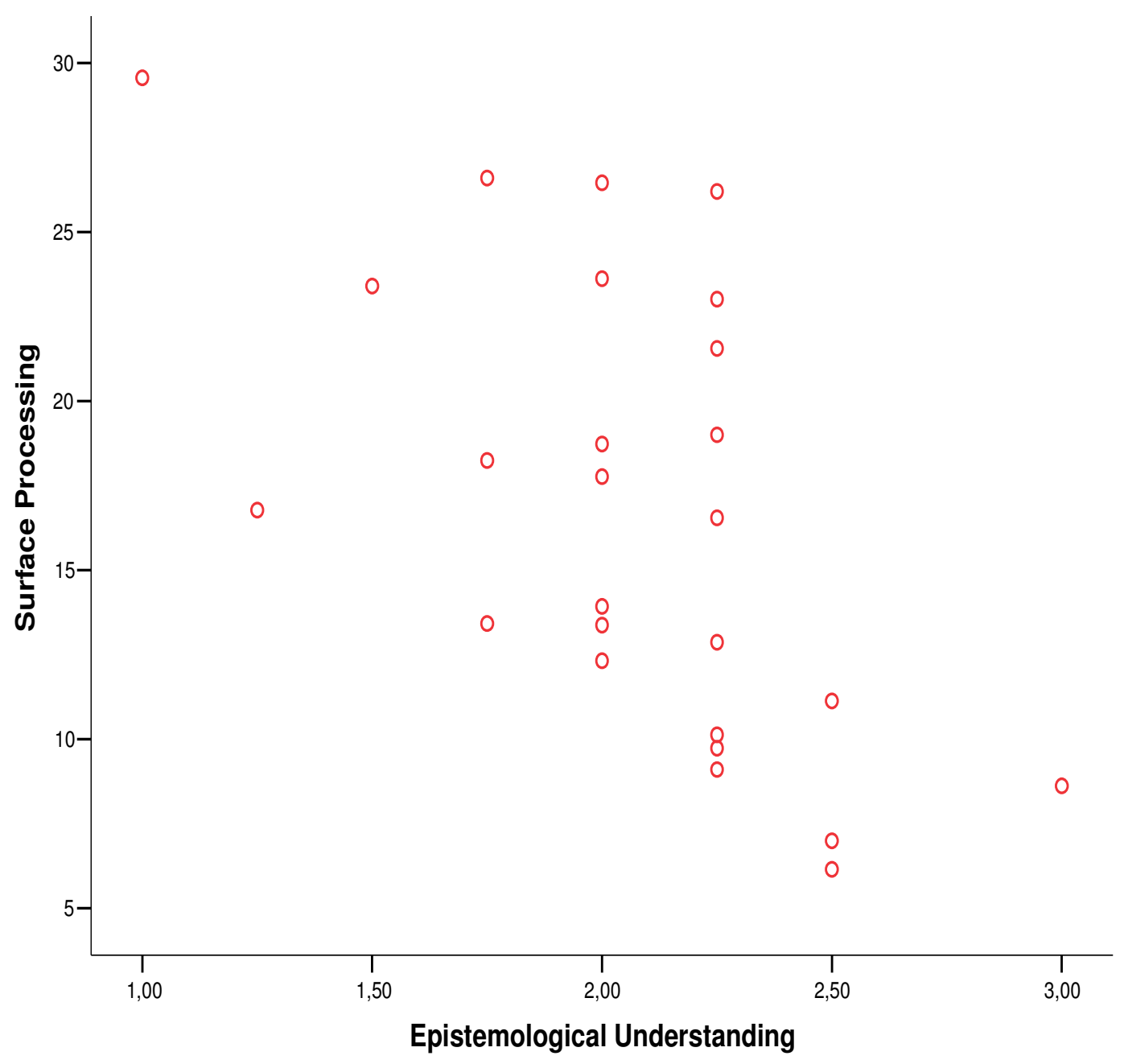

42

43 ( . 6

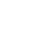
9 1 . (2) 56 


\section{Figure 3.}

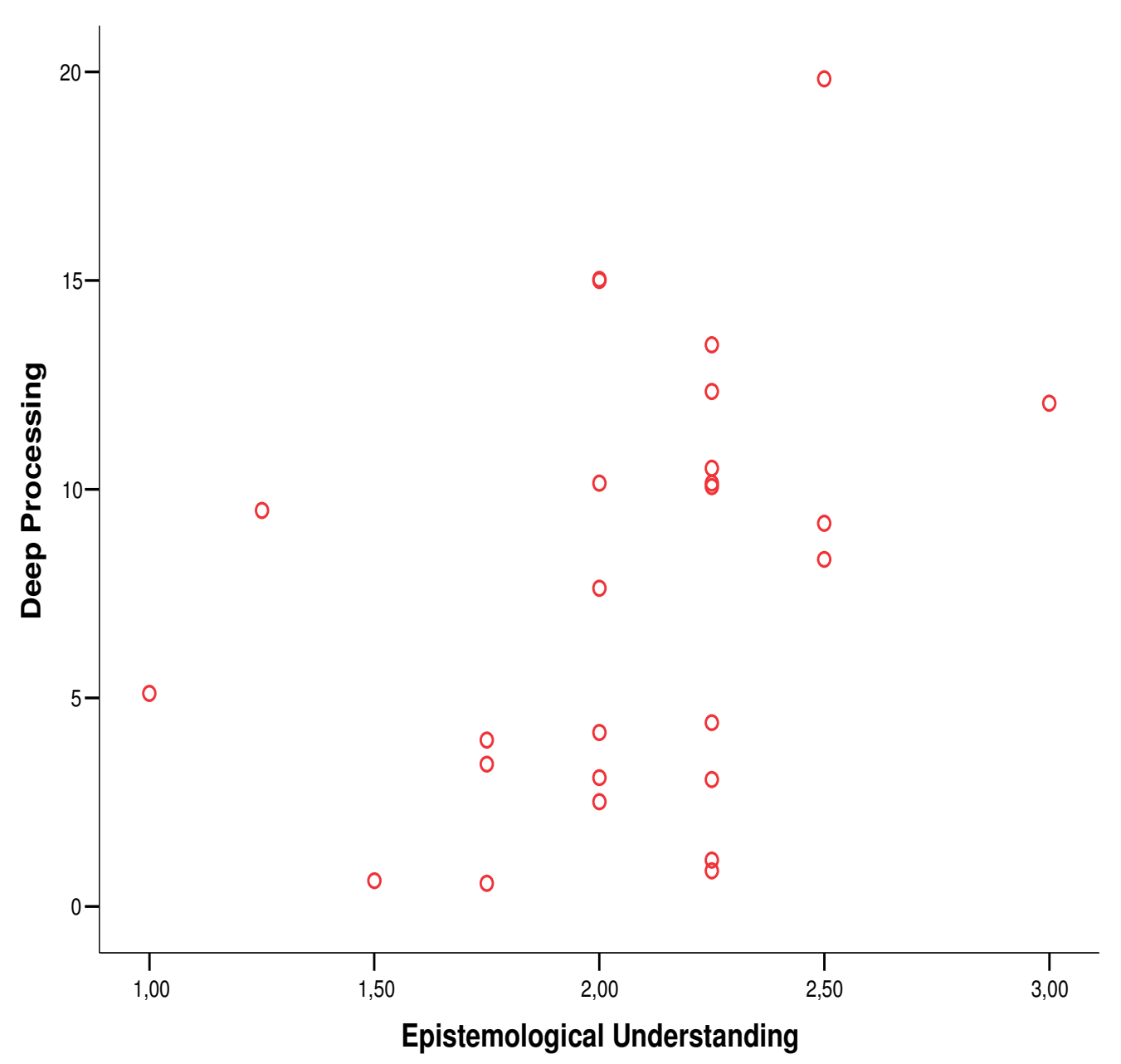

41

42

43 